\title{
WISUDA LENGGER GIYANTI SEBAGAI DAYA TARIK WISATA DI KABUPATEN WONOSOBO
}

\author{
Syahrul Akbar', Evi Noviyanti ${ }^{2}$, Ute Lies Siti Khadijah ${ }^{3}$ Awaludin Nugraha ${ }^{4}$ \\ ${ }^{1,2,3,4}$ Sekolah Pascasarjana, Universitas Padjadjaran, J1. Dipati Ukur No. 35 Kota Bandung, 40132 \\ ${ }^{2}$ Program Studi Magister Pariwisata Berkelanjutan \\ E-mail: syahrul19001@mail.unpad.ac.id ; evi.novianti@unpad.ac.id ; ute.lies@unpad.ac.id ; \\ awaludin.nugraha@unpad.ac.id
}

\begin{abstract}
ABSTRAK
Kekuatan event budaya terletak pada kemampuannya dalam memenuhi tantangan imajinasi pengunjung dan penyelenggaranya, serta menjelajahi kemungkinan-kemungkinan tradisi budaya sebagai produk pariwisata. Sehingga event budaya sering dijadikan atraksi wisata di sebuah destinasi pariwisata. Selain dapat meningkatkan kunjungan wisatawan, event budaya juga mampu untuk meningkatkan lama tinggal wisatawan, serta jumlah pengeluaran wisatawan di sebuah destinasi. Dengan potensi tersebut, banyak destinasi pariwisata kemudian mengemas berbagai ritus budaya menjadi sebuah event budaya yang menarik, unik dan sarat nilai-nilai budaya, namun tidak meninggalkan esensi kesakralan ritus budaya tersebut. Penelitian ini mengambil event budaya Wisuda Lengger Giyanti di Kabupaten Wonosobo sebagai obyek dalam penelitian. Metode yang digunakan adalah penelitian kualitatif dengan data yang terdiri dari data primer dan data sekunder. Data primer merupakan hasil wawancara mendalam melalui telepon dengan Penyelenggara Gelaran Wisuda Lengger, sedangkan data sekunder diperoleh dari tinjauan pustaka mengenai teori penyelenggaraan event dan festival, serta literatur terkait dengan Wisuda Lengger Giyanti. Analisis dalam penelitian ini menggunakan pendekatan pariwisata budaya dan teori manajemen penyelenggaraan event sehingga dapat mengidentifikasi aspek-aspek kebudayaan dalam gelaran Wisuda Lengger Giyanti.
\end{abstract}

Kata kunci; pariwisata budaya; event; Lengger; Wonosobo

\section{WISUDA LENGGER GIYANTI AS A TOURIST ATTRACTION IN WONOSOBO REGENCY}

\begin{abstract}
The strength of a cultural event lies in its ability to meet the challenges of the imagination of visitors and their organizers, and explore the possibilities of cultural traditions as tourism products. So that cultural events are often used as tourist attractions in a tourism destination. Besides being able to increase tourist visits, cultural events are also able to increase the length of stay of tourists, as well as the amount of tourist spending at a destination. With this potential, many tourism destinations then package various cultural rites into an interesting cultural event, unique and full of cultural values, but do not leave the essence of the sacredness of the cultural rites. This study took the Wisuda Lengger Giyanti cultural event in Wonosobo Regency as an object of the research. The method used is qualitative research with data consisting of primary data and secondary data. Primary data is the result of in-depth interviews via telephone with the Organizer of the Wisuda Lengger Event, while secondary data is obtained from a literature review on the theory of organizing events and festivals, as well as literature related to Wisuda Lengger Giyanti. The analysis in this study uses a cultural tourism approach and event management theory so that it can identify cultural aspects in the Wisuda Lengger Giyanti event.
\end{abstract}

Key words; Cultural tourism; event; Lengger; Wonosobo

\section{PENDAHULUAN}

Kabupaten Wonosobo merupakan salah satu kabupaten di Provinsi Jawa Tengah. Kata Wonosobo diambil dari bahasa Jawa, wanasaba, bila diartikan secara harfiah memiliki makna "tempat berkumpul di hutan." Hal ini didukung oleh letak geografis sebagian besar wilayah Kabupaten Wonosobo yang berada di wilayah pegunungan, di antaranya yaitu Gunung Sindoro, Gunung Sumbing, Gunung Prau, serta Dataran Tinggi Dieng.

Keuntungan geografis Wonosobo yang berada di wilayah pegunungan menjadikan Wonosobo sebagai destinasi wisata yang mengandalkan daya tarik wisata alam. Di antara daya tarik wisata alam yang terkenal di
Wonosobo adalah Dataran Tinggi Dieng, Golden Sunrise Sikunir, Telaga Warna, dan Telaga Menjer.

Selain wisata alam, kekayaan warisan seni dan budaya yang hidup dan berkembang di Wonosobo juga berpotensi untuk dijadikan daya tarik wisata budaya. Salah satu seni tradisional yang berkembang di Wonosobo adalah Tari Lengger Wonosobo. Tari Lengger khas Wonosobo ini dikembangkan dari kesenian Tari Tayub yang populer sebagai seni tradisional kerakyatan. Kemudian dirintis dan dipopulerkan di Dusun Giyanti, Kabupaten Wonosobo oleh Bapak Gondhowinangun pada Tahun 1910.

Sebagai upaya untuk melestarikan Tari Lengger, dan memosisikan citra Dusun Giyanti sebagai Desa yang 
mencetak penari Lengger di Jawa Tengah, masyarakat Dusun Giyanti kemudian berikhtiar menyelenggarakan sebuah sebuah gelaran budaya bertajuk Wisuda Lengger Giyanti. Gelaran ini dilaksanakan pada bulan September 2019, yang dirangkaikan dengan acara Rakanan Giyanti. Untuk Wisuda Lengger Giyanti sendiri baru dilaksanakan dua tahun belakangan, yaitu pada tahun 2018 dan 2019, sedangkan Rakanan Giyanti atau Rakanan Suro Giyanti telah dilaksanakan sejak Dusun Giyanti ini terbentuk pada Tahun 1755 atau sekitar 264 tahun yang lalu. Rakanan Giyanti merupakan ritual adat untuk mengenang jasa-jasa para leluhur yang telah mendirikan Dusun Giyanti, serta sebagai ungkapan syukur kepada Pencipta atas karunia rezeki dan berkah yang dilimpahkan kepada masyarakat desa.

Wisuda Lengger Giyanti atau "Wisuda Lengger Rakanan Suro Giyanti 2019" merupakan sebuah ritus budaya yang telah berlangsung di Dusun Giyanti, Kecamatan Selomerto, Kabupaten Wonosobo sejak tahun 1980-an. Merujuk pada nama gelaran ini, Wisuda Lengger Giyanti merupakan serangkaian tahapan ritus budaya yang harus dilakukan oleh peserta wisuda yang telah mendalami seni Tari Lengger baik secara teoritis maupun secara praktikal di beberapa Sanggar Tari di Dusun Giyanti, sebelum secara resmi dikukuhkan menjadi seorang Penari Lengger. Namun pada awal mula perkembangan tari Lengger di Dusun Giyanti, ritus ini berlaku eksklusif dan cenderung tertutup, karena yang terlibat hanya tetua adat, pengurus Sanggar Tari Lengger, dan calon Penari Lengger.

Wisuda Lengger Giyanti menarik untuk diteliti karena beberapa faktor, yaitu:

1. Tari Lengger merupakan seni tradisional kerakyatan yang hidup dan berkembang di Dusun Giyanti, sebuah kearifan lokal yang diwariskan secara turun temurun oleh nenek moyang masyarakat Dusun Giyanti (Puspita \& Sulandari, 2016);

2. Wisuda Lengger Giyanti merupakan bentuk komodifikasi budaya dari ritus budaya pengukuhan penari Lengger di Dusun Giyanti yang pada awal mula perkembangan Seni Tari Lengger bersifat eksklusif dan cenderung tertutup (Taufani, 2019);

3. Secara berturut-turut Wisuda Lengger Giyanti masuk ke dalam daftar Calendar of Events Kabupaten Wonosobo pada tahun 2018 dan 2019 untuk meningkatkan kunjungan wisatawan di Kabupaten Wonosobo.

Dari ketiga faktor tersebut dapat diketahui bahwa yang menjadi fokus dalam penelitian ini adalah pariwisata warisan budaya (Cultural and Heritage Tourism) dengan ruang lingkup yang mencakup otentisitas dan komodifikasi budaya dan event budaya.

Dalam pariwisata budaya selalu terdapat tarik ulurbahkan cenderung terdapat tegangan - antara otentisitas dan komodifikasi budaya. Argumentasi dibangun berdasarkan asumsi bahwa warisan budaya - baik yang berwujud dan tidak berwujud (tangible and intangible) yang otentik atau asli bersifat positif karena dapat menjadi faktor yang menarik kunjungan wisatawan.

Studi yang dilakukan oleh (Zhou, Zhang, Zhang, \& $\mathrm{Li}$, 2018) menunjukkan bahwa otentisitas negatif yang cenderung diabaikan untuk dilestarikan tidak berterima baik bagi wisatawan maupun penduduk setempat untuk dijadikan atraksi wisata. Otentisitas negatif dalam penelitian ini didasarkan pada obyek, situs, event atau budaya yang berdasarkan persepsi wisatawan maupun penduduk lokal kurang bernilai. Nilai-nilai prinsip dari peradaban modern di mana wisatawan dan penduduk lokal sekarang hidup, memegang peranan penting dalam mekanisme pembentukan otentisitas negatif (Zhou et al., 2018).

Sedangkan menurut (Chhabra, 2019) pandangan diskursif ditawarkan tentang bagaimana otentisitas yang berbeda dilegitimasi dan didekonstruksi secara kritis dan dibangun kembali dalam proses otentikasi untuk menggarisbawahi adanya intervensi kekuasaan dan otoritas. Selanjutnya disimpulkan bahwa otentisitas merupakan konstruksi kebudayaan yang secara terus menerus mengalami "getaran" dan revisi sebagai akibat fleksibilitas kebudayaan yang terus berkembang untuk menghadapi perubahan kekuatan lingkungan mikro dan makro.

Penelitian otentisitas lainnya menggunakan pendekatan sosiospasial untuk menunjukkan bahwa otentisitas dapat diciptakan dan dialami melalui serangkaian pengaturan komersial yang melibatkan desain, organisasi dan manajemen penyelenggaraan festival musik yang dikreasikan bersama-sama dengan peserta untuk menghadirkan pengalaman yang otentik (Szmigin, Bengry-howell, Morey, Griffin, \& Riley, 2017).

Sebaliknya argumentasi komodifikasi mendasarkan pada asumsi bahwa kebudayaan beserta aspek-aspek yang melingkupinya merupakan aset jika dihubung-kaitkan dengan pariwisata, yang secara definisi dapat diperjualbelikan (Macleod, 2006). Lebih lanjut Macleod menyimpulkan bahwa komodifikasi budaya yang dieksploitasi untuk kepentingan destinasi pariwisata oleh para pengambil kebijakan, jika mengabaikan aspek-aspek kebudayaan yang dapat memberikan manfaat terhadap penduduk lokal dan wilayahnya, cenderung akan mengarah kepada globalisasi pengalaman budaya yang menafikan kekayaan dan keragaman budaya yang kompleks.

Mendukung penelitian yang dilakukan oleh Macleod, terdapat studi kasus tentang proses komodifikasi budaya di Desa Wisata Kembangarum, Daerah Istimewa Yogyakarta (Ristiawan, 2018). Hasil penelitian menunjukkan bahwa proses komodifikasi merupakan bagian dari politisasi budaya yang tercakup dalam agenda pemberdayaan masyarakat. Sebaliknya proses komodifikasi yang melibatkan proyek investasi dari pihak swasta menimbulkan konflik di masyarakat Desa Wisata Kembangarum atas usaha privatisasi tradisi lokal untuk kepentingan Investor.

Beberapa aspek kebudayaan yang sering dikomodifikasi dalam upaya untuk menarik kunjungan wisatawan adalah atraksi sosial budaya, upacara keagamaan, dan festival, karena aspek-aspek tersebut diwariskan dari generasi ke generasi dan terus menerus diciptakan kembali oleh masyarakat dan kelompokkelompoknya sebagai respons terhadap lingkungan mereka, interaksinya dengan alam dan sejarah mereka, serta memberikan rasa identitas dan kontinuitas, sehingga 
mendorong penghormatan terhadap keanekaragaman budaya dan manusia (Santa \& Tiatco, 2019).

Salah satu aspek kebudayaan yang menjadi obyek penelitian adalah atraksi mengenakan pakaian tradisional kerajaan pada Festival Budaya Kerajaan di Seoul, Korea Selatan. Penelitian ini mengukur tingkat kepuasan wisatawan melalui lima dimensi dalam penyelenggaraan festival yaitu, keseruan, pelarian dari rutinitas, tempat penyelenggaraan, rasa kebersamaan dengan masyarakat lokal, serta kesakralan sebuah festival (Lee \& Lee, 2019). Berdasarkan hasil penelitian menunjukkan bahwa atraksi memakai Pakaian Tradisional Kerajaan, Hanbok, memiliki peran yang sangat signifikan terhadap tingkat kepuasan wisatawan terhadap lima dimensi penyelenggaraan festival tersebut (Lee \& Lee, 2019).

Peranan event dalam pengembangan sebuah destinasi pariwisata sangat signifikan (Allen, O'Toole, McDonnel, \& Harris, 2002; Risteski \& Risteski, 2015). Karena event dapat berfungsi menarik kunjungan wisatawan, meningkatkan lama tinggal dan pengeluaran wisatawan, membentuk Citra destinasi pariwisata, serta memosisikan destinasi pariwisata sehingga menjadikan satu destinasi menjadi lebih kompetitif untuk pasar wisatawan (Allen et al., 2002; Aristrawati, 2018; Dai, Hein, \& Zhang, 2019; Laing, 2018; Liu, 2014; Rahayu, 2018).

Sebuah penelitian tentang dampak penyelenggaraan event budaya terhadap citra kota, dilakukan di Rotterdam. Penelitian ini dilakukan berdasarkan asumsi bahwa semakin banyak kota/destinasi yang menggunakan event budaya untuk meningkatkan citra mereka, merangsang pertumbuhan kota/destinasi, serta menarik kunjungan wisatawan dan membuka peluang investasi (Richards \& Wilson, 2004). Dari hasil kuesioner yang disebar kepada 2.000 pengunjung dan penduduk setempat, diperoleh kesimpulan bahwa penyelenggaraan Event Budaya di Rotterdam mampu membentuk citra Rotterdam sebagai Kota Budaya di Eropa (Richards \& Wilson, 2004).

Merujuk pada penelitian sebelumnya tentang otentisitas dan komodifikasi budaya, serta event budaya, fokus penelitian antara lain terletak pada persepsi wisatawan dan penduduk lokal terhadap otentisitas negatif pariwisata budaya (Zhou et al., 2018), intervensi kekuasaan dan otoritas terhadap otentisitas (Chhabra, 2019), pendekatan sosiospasial untuk menghadirkan pengalaman otentik dari festival musik (Szmigin et al., 2017), komodifikasi budaya oleh pengambil kebijakan (Macleod, 2006), proses komodifikasi budaya sebagai bagian politisasi kebudayaan (Ristiawan, 2018), komodifikasi budaya sebagai respons terhadap lingkungan, serta interaksi dengan alam dan sejarah penduduk lokal (Santa \& Tiatco, 2019), tingkat kepuasan wisatawan terhadap dimensi penyelenggaraan festival budaya (Lee \& Lee, 2019), serta peran event budaya terhadap citra kota (Richards \& Wilson, 2004). Dari penelitian sebelumnya diketahui bahwa belum ada penelitian yang menjadikan aspek-aspek budaya dalam penyelenggaraan sebuah event untuk menarik kunjungan wisatawan sebagai fokus penelitiannya.

Sehingga, berdasarkan fokus penelitian sebelumnya dapat dirumuskan tujuan penelitian ini adalah untuk mengidentifikasi aspek-aspek budaya dalam penyelenggaraan event Wisuda Lengger Rakanan Suro Giyanti 2019 sebagai daya tarik wisata di Kabupaten Wonosobo.

\section{METODE}

Metode yang digunakan adalah penelitian kualitatif dengan data yang terdiri dari data primer dan data sekunder. Data primer merupakan hasil wawancara mendalam melalui telepon dengan Penyelenggara Gelaran Wisuda Lengger, sedangkan data sekunder diperoleh dari tinjauan pustaka mengenai teori penyelenggaraan event dan festival, serta literatur terkait dengan Wisuda Lengger Giyanti. Analisis dalam penelitian ini menggunakan pendekatan Cultural and Heritage Tourism dan teori manajemen penyelenggaraan event sehingga dapat mengidentifikasi aspek-aspek kebudayaan dalam gelaran Wisuda Lengger Giyanti.

\section{HASIL DAN PEMBAHASAN}

\section{Tari Lengger dan Perkembangannya}

Berdasarkan sejarah yang berkembang di Dusun Giyanti, Tari Lengger merupakan hasil pengembangan dari Tari Tayub. Walaupun merupakan produk turunan dari kesenian lain, terdapat perbedaan mendasar antara Tari Tayub dan Tari Lengger. Perbedaan itu terletak pada penarinya. Jika pada kesenian Tayub, penarinya diwajibkan harus seorang gadis perawan, sedangkan pada kesenian Lengger, penarinya bisa laki laki maupun perempuan.

Pada awal mula perkembangannya, Tari Lengger sering dianggap kesenian kelas 2 (dua). Konotasi negatif tersebut disebabkan oleh kecenderungan para Seniman Lengger yang lebih sering mempertontonkan sensualitas penarinya. Selain itu, pada saat pertunjukan selalu dibarengi dengan sajian minuman keras untuk para spektatornya. Namun setelah ajaran Islam yang dibawa oleh Walisongo masuk sampai ke Wonosobo, Tari Lengger kemudian berubah menjadi sarana dakwah yang mengajarkan budi pekerti.

Perubahan tersebut turut pula mempengaruhi makna dari Tari Lengger. Terdapat beberapa versi etimologi dari kata Lengger sendiri. Di antaranya memaknai kata Lengger berasal dari dua kata, yaitu "Leng," dan "Ger." Leng berarti laki-laki dan Ger berarti perempuan. Sehingga jika digabungkan makna kata Lengger menjadi laki-laki yang menyerupai perempuan. Hal ini dapat dibenarkan karena di beberapa bentuk Tari Lengger, terkadang seorang penari laki-laki dalam pertunjukannya harus berpenampilan menyerupai seorang wanita.

Makna lain dari kata Lengger berasal dari kata "elingo Ngger" yang memiliki padanan makna "ingatlah Nak." Pemaknaan ini dipengaruhi oleh ajaran agama Islam yang dibawa oleh Walisongo. Sehingga pertunjukan Tari Lengger menjadi media untuk menyampaikan pesan agar setiap orang harus selalu ingat kepada Sang Pencipta dan berbuat baik kepada sesama. 
Dalam perkembangannya, Tari Lengger kemudian muncul dalam dua langgam besar, yaitu Lengger Wonosobo dan Lengger Banyumas. Pada Lengger Banyumas tariannya bersifat ritual, karena selalu dimulai dengan pembacaan doa dan Penari Lengger keluar diiringi gending sesajen berupa Lancaran Sekargadung. Selain itu Lengger Banyumas tidak mengenakan topeng, penarinya mendapat saweran dari penonton, dan penonton selalu diajak untuk ikut menari di atas panggung.

Sedangkan Lengger Wonosobo dalam pertunjukannya selalu ditarikan berpasangan antara lelaki dan wanita. Penari laki-laki mengenakan topeng dan penari wanita sebagai Lengger. Sehingga sering disebut tari Topeng Lengger. Selain itu Tari Lengger Wonosobo banyak menceritakan epos. Epos atau cerita yang diangkat dalam Lengger Wonosobo adalah kisah asmara antara Panji Asmoro Bangun yang berasal dari Kerajaan Jenggala dengan Dewi Sekartaji dari Kerajaan Kediri.

Lika-liku perjalanan cinta antara Panji Asmoro Bangun dengan Dewi Sekartaji ini kemudian dimunculkan ke dalam tarian topeng Lengger. Berdasarkan epos tersebut, terdapat sekitar 60 judul tari topeng Lengger. Masing-masing judul memiliki corak karakter dan ceritanya sendiri-sendiri. Namun karena menyesuaikan permintaan pasar, karakter topeng Lengger yang sering ditampilkan hanya sampai 30 karakter topeng.

Tari Lengger dikenalkan dan dirintis di Dusun Giyanti pada Tahun 1910, atas jasa Bapak Gondhowinangun, salah seorang seniman Lengger di Wonosobo. Kemudian kesenian tradisional kerakyatan ini dikembangkan lagi oleh Ki Hadi Soewarno pada tahun 1960-an. Almarhum Ki Hadi Soewarno menjadi peletak dasar perubahan kesenian Tari Lengger Wonosobo. Tari Lengger yang semula ditarikan oleh laki-laki berpenampilan perempuan, kemudian dirubah menjadi Tari Lengger yang ditarikan oleh perempuan semua. Perubahan ini kemudian diteruskan sampai dengan Lengger yang dikenal saat ini.

Selain itu, Ki Hadi Soewarno juga menggagas Ritus Wisuda Lengger yang dimulai sejak tahun 1980an. Di awal pelaksanaannya tidak ada penggunaan istilah Wisuda Lengger, hanya saja terdapat beberapa ritus yang harus dilakukan untuk mengukuhkan penari tersebut sebagai seorang penari Lengger.

\section{Desa Wisata Giyanti}

Dusun Giyanti merupakan salah satu dusun yang terletak di Desa Kadipaten, Kecamatan Selomerto, Kabupaten Wonosobo. Masyarakat di dusun ini masih menghormati tradisi dan budaya. Salah satu tradisi yang masih dilaksanakan adalah Nyadran Tenongan. Selain itu, dusun ini terkenal sebagai dusun yang melahirkan banyak Penari Lengger sebagai salah satu kesenian tradisional di Jawa Tengah.

Dengan potensinya tersebut, Dusun Giyanti kemudian ditetapkan sebagai salah satu Desa Wisata di Kabupaten Wonosobo dengan nama Desa Wisata
Giyanti. Desa Wisata ini berbasis wisata budaya yang menjaga keeksotisan ritual dan adat tradisi yang ada tanpa menutup diri dengan perkembangan zaman.

Setelah dibentuk pada tahun 2006, Desa Wisata Giyanti sempat mati suri. Beberapa tahun kemudian beralih nama menjadi Desa Wisata Gerbang Dewa, yang merupakan singkatan dari "Gerakan Bangkit Desa Wisata." Namun nama tersebut kembali dirubah menjadi Desa Wisata Giyanti karena terkesan tendensius dan tidak mengakomodir kearifan lokal Dusun Giyanti.

Desa Wisata Giyanti mulai bangkit kembali pada tahun 2015, dan mengokohkan dirinya menjadi pusat pelatihan tari Lengger di Wonosobo. Produk budaya yang diandalkan desa wisata ini antara lain tari tradisional dan tari kontemporer, yaitu Tari Lengger, Tari Kuda Kepang, dan Tari Topeng. Untuk mendukung pelestarian seni budaya tersebut, terdapat 3 (tiga) sanggar Seni Tari, yaitu Sanggar Tunas Mekar Budaya yang dikelola oleh dusun, serta Sanggar Rukun Putri Budaya dan Sanggar Sudamala yang dikelola oleh anggota masyarakat Dusun Giyanti.

Sebagai desa wisata, Dusun Giyanti telah menyiapkan paket wisata Trip of Giyanti, yaitu paket wisata yang mengajak wisatawan untuk tinggal dan merasakan kehidupan sosial, seni dan budaya di Desa Wisata Giyanti. Untuk menunjang kunjungan wisatawan, sudah tersedia 10 homestay dengan jumlah kamar sebanyak 20 buah untuk kapasitas tamu sebanyak 50 orang.

\section{Rakanan Suro Giyanti}

Selain kesenian Lengger, Desa Wisata Giyanti juga memiliki keunikan lokal lainnya berupa ritus budaya Nyadran. Nyadran merupakan upacara yang diadakan setiap tahun pada bulan Muharam atau bulan Sura dalam kalender Jawa di hari Jumat Kliwon. Ritus ini dilaksanakan untuk menghormati dan mendoakan arwah leluhur pendiri Dusun Giyanti. Karena rutin dilaksanakan tiap tahun, Nyadran kemudian dijadikan event budaya tahunan di Desa Wisata Giyanti.

Pelaksanaan gelaran Wisuda Giyanti tidak dapat dilepaskan dari tradisi Nyadran Tenongan masyarakat Dusun Giyanti atau yang dikenal dengan Rakanan Suro Giyanti. Disebut sebagai Rakanan karena pada saat prosesi Nyadran selalu disediakan rakanan yaitu tenong yang berisi jajanan pasar, nasi rames dan buahbuahan. Sedangkan Suro dan Giyanti adalah keterangan waktu pelaksanaan Nyadran di bulan Suro atau Muharam serta Giyanti sebagai nama tempat atau dusun pelaksanaan Nyadran tersebut.

Berdasarkan sejarah berdirinya Dusun Giyanti, Nyadran dilaksanakan atas wasiat dari Kyai Mertalaya yang merupakan salah seorang pendiri dari Dusun Giyanti. Beliau berwasiat agar anak cucu warga Dusun Giyanti melaksanakan upacara atau Nyadran dengan tujuan sebagai wujud syukur atas nikmat Tuhan, serta sebagai monumen budaya untuk mengingat berdirinya Dusun Giyanti (Tahun 1755) sebagai imbas dari Perjanjian Giyanti (yaitu perjanjian antara Sri Sunan Pakubuwono III, Pangeran Mangkubumi yang 
kemudian bergelar Sri Sultan Hamengkubuwono, dan Gubernur Jawa Utara, Nicolaas Hartingh, yang membagi kerajaan Mataram menjadi dua).

Dalam pelaksanaannya prosesi Nyadran dilakukan pada hari Jumat Kliwon bulan Suro dengan ziarah ke makam para leluhur, menyiapkan tenongan berisi hasil bumi, serta pertunjukan kesenian khas Dusun Giyanti.

Kemudian atas wangsit dari Kyai Mertalaya kepada Alm. Ki Hadi Soewarno, pada Tahun 1975 Nyadran Tenongan selalu disertai dengan pertunjukan Tari Lengger. Masyarakat Dusun Giyanti percaya jika tidak melakukan Upacara Nyadran Tenongan akan mendatangkan musibah seperti penyakit, gagal panen dan bala lainnya. Namun mulai tahun 2018 Nyadran Tenongan dikomodifikasi menjadi gelaran budaya Rakanan Giyanti yang mengambil tema "The Legend of Lengger Giyanti" dan pada Tahun 2019 tema Rakanan Giyanti menjadi "The Awakening of Lengger Punjen." Tema ini diambil berdasarkan kearifan lokal di Dusun Giyanti, dusun di mana kesenian Tari Lengger khas Wonosobo tumbuh dan berkembang bersama dengan masyarakatnya. Selain itu, salah satu rangkaian puncak dari Rakanan Giyanti ini adalah mengukuhkan para Penari Lengger yang telah melewati beberapa ritus budaya. Proses komodifikasi prosesi Wisuda Lengger Giyanti dilakukan oleh kelompok masyarakat pengelola Desa Wisata Giyanti.

\section{Wisuda Lengger Giyanti}

Kearifan lokal masyarakat Dusun Giyanti dalam bentuk Tari Lengger merupakan warisan turun temurun dari nenek moyang masyarakat Dusun Giyanti. Dalam perkembangannya kesenian tradisional Tari Lengger mengalami banyak pasang surut. Hal ini diakibatkan oleh semakin tergerusnya kesenian tradisional kerakyatan oleh ragam hiburan modern. Gelaran Wisuda Lengger Giyanti secara simbolis merupakan perwujudan kesadaran kolektif masyarakat Dusun Giyanti untuk melestarikan warisan nenek moyang mereka.

Pelaksanaan event budaya Wisuda Lengger Giyanti dilatarbelakangi oleh pesatnya perkembangan kesenian Lengger di Wonosobo. Ini ditunjukkan dengan semakin meningkatnya minat generasi muda di Wonosobo khususnya untuk mempelajari dan mendalami kesenian tradisional Tari Lengger. Fenomena tersebut ternyata tidak diimbangi dengan mutu dan kualitas penari Lengger. penurunan mutu dan kualitas ini disebabkan oleh banyaknya penari Lengger yang belajar kesenian tersebut secara autodidak, bahkan hanya melalui rekaman video di kanal media sosial penyedia video seperti Youtube. Sementara pengetahuan kesenian Lengger secara komprehensif belum mereka kuasai dengan baik.

Penyelenggaraan Wisuda Lengger Giyanti sebagai event budaya bertujuan antara lain:

1. Untuk menambah khasanah keilmuan khususnya di bidang kesenian Lengger;
2. Untuk menambah kualitas dan kuantitas, serta memberi karakter dan corak identitas kesenian Lengger di Wonosobo;

3. Sebagai panduan bagi setiap Seniman Lengger dalam menjalankan profesinya dengan mempertahankan komitmennya terhadap kehidupan berkesenian; dan

4. Untuk mengangkat martabat profesi Lengger agar tidak mudah dipandang sebelah mata.

Dalam prosesi Wisuda Lengger Giyanti terdapat beberapa pihak yang terlibat, seperti yang dapat di lihat pada tabel 1 di bawah ini:

Tabel 1. Jabatan dan Tugas dalam Prosesi Wisuda Lengger Giyanti

\begin{tabular}{|c|c|c|c|}
\hline No. & Nama & Tugas & Keterangan \\
\hline 1. & Kurator & $\begin{array}{l}\text { Menyeleksi } \\
\text { para } \\
\text { pendaftar } \\
\text { calon } \\
\text { wisudawati }\end{array}$ & $\begin{array}{l}\text { Pendaftaran } \\
\text { wisuda dibuka } \\
\text { oleh panitia, } \\
\text { kemudian } \\
\text { diseleksi dengan } \\
\text { berbagai macam } \\
\text { kriteria, yang } \\
\text { lolos berhak untuk } \\
\text { mengikuti proses } \\
\text { berikutnya. }\end{array}$ \\
\hline 2. & Narasumber & $\begin{array}{l}\text { Memberikan } \\
\text { pembekalan } \\
\text { teoritis dan } \\
\text { praktek } \\
\text { kesenian } \\
\text { Lengger }\end{array}$ & $\begin{array}{l}\text { Materi } \\
\text { pembekalan } \\
\text { meliputi: sejarah } \\
\text { Lengger, Etika } \\
\text { Filosofi Lengger, } \\
\text { Profesionalisme } \\
\text { Lengger, Strategi } \\
\text { Marketing, dan } \\
\text { Penyeragaman } \\
\text { Gerak/Praktek } \\
\text { Tari Gambyong } \\
\text { Lengger. }\end{array}$ \\
\hline 3. & Penjamas & $\begin{array}{l}\text { Memimpin } \\
\text { ritual } \\
\text { jamasan dan } \\
\text { larung sesaji }\end{array}$ & $\begin{array}{l}\text { Dilakukan oleh } \\
\text { Tetua atau mantan } \\
\text { penari Lengger }\end{array}$ \\
\hline 4. & $\begin{array}{l}\text { Manggala } \\
\text { Wisuda }\end{array}$ & $\begin{array}{l}\text { Mewisuda } \\
\text { dan } \\
\text { memimpin } \\
\text { pembacaan } \\
\text { sumpah }\end{array}$ & $\begin{array}{l}\text { Dilakukan oleh } \\
\text { Anak, Cucu atau } \\
\text { Kerabat dari Trah } \\
\text { Alm. Ki Hadi } \\
\text { Soewarno. }\end{array}$ \\
\hline
\end{tabular}

(Sumber: Hasil Penelitian, 2019)

Terdapat 9 (sembilan) tahapan dalam prosesi Wisuda Lengger Giyanti, yaitu pembekalan peserta, Lengger Mutih, Simpuh Lengger, jamasan, larung sesajen, prosesi wisuda, ikrar Catur Dharma Lengger, penyematan bros, dan Seblak Sampur.

\section{Pembekalan Peserta}

Sebelum melaksanakan wisuda, semua peserta (Calon Penari Lengger) diberikan pembekalan dan pelatihan secara singkat, baik pengetahuan secara teoritis maupun praktek. Materi yang diberikan antara lain: Sejarah, Filosofi, dan Etika Lengger, Pengenalan Catur Dharma Lengger yaitu ikrar yang akan diucapkan pada saat prosesi Wisuda Lengger, Strategi Marketing, serta Penyeragaman Gerak atau Praktek Tari Gambyong Lengger. 
Pembekalan peserta ini dilaksanakan sehari penuh bertempat di Pendapa Sanggar Kertajanti, Desa Wisata Giyanti.

\section{Lengger Mutih}

Pada tahapan ini peserta harus melakukan tirakat atau prihatin selama 3 hari menjelang pelaksanaan wisuda. Prosesi ini bisa berupa Puasa Mutih atau Puasa Biasa, dan bersifat situasional tergantung kepercayaan dan keteguhan hati asing-masing peserta. Terdapat perbedaan pada prosesi ini jika dibandingkan dengan prosesi yang dilakukan di tahun 1980 -an, masa awal penetapan pelaksanaan ritual pengukuhan Penari Lengger oleh alm. Ki Hadi Soewarno. Pada masa itu calon Penari Lengger diwajibkan untuk berpuasa selama 40 hari tanpa putus.

\section{Simpuh Lengger}

Calon Penari Lengger mengikuti rangkaian acara Rakanan Giyanti, mulai dari Ziarah Makam Leluhur, Kirab Tenong, hingga "Ngabulake." Ziarah Makam Leluhur merupakan ritus untuk mendoakan para Leluhur "Bubak Senggani" atau The Founding Father di Wilayah Giyanti. Secara simbolis ziarah leluhur ini dimaknai sebagai napak tilas perjuangan para The Founding Father dalam membangun Dusun Giyanti sampai berkembang hingga saat ini. Kirab Tenong yaitu membawa tenong (nampan) berisi hasil bumi, nasi bungkus, dan aneka jajan pasar yang secara simbolis menandakan rasa syukur masyarakat Dusun Giyanti kepada Tuhan Yang Maha Esa atas limpahan karunia bagi kesejahteraan warga Giyanti.
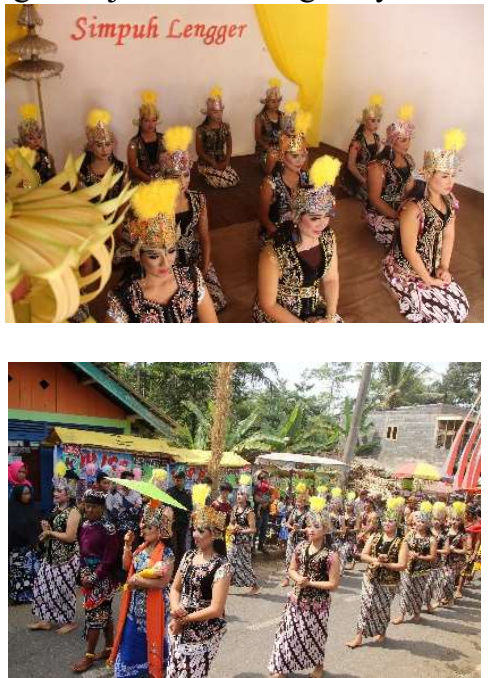

Gambar 1. Prosesi Simpuh Lenggger dan Kirab Tenong

Pada saat Sesepuh "Ngabulake" atau memanjatkan doa, para peserta duduk bersimpuh dengan hikmat, sebagai wujud kemantapan berserah diri pada Yang Maha Kuasa agar diberikan kekuatan dalam menjalankan rangkaian prosesi Wisuda Lengger yang akan segera dijalani. Pada tahapan ini para Peserta mengenakan pakaian Kostum Lengger Lengkap.
Prosesi jamasan ini yaitu prosesi mandi atau siram atau jamas bagi para peserta di sungai tempat pertemuan 2 aliran sungai (Kali Tempuk/Tempuran) Silengsar. Tahapan ini secara simbolik merupakan perwujudan "reresik sesuci diri" atau ritual membersihkan diri. Karena peserta yang diwisuda harus dalam keadaan suci baik lahir maupun batin.

Peserta dijamas secara berurutan, satu per satu dengan menggunakan air jamasan yang sudah dicampur dengan Kembang Leson yang terdiri dari bunga mawar, melati, kenanga dan katil. Prosesi ini melambangkan wujud manunggaling atau bersatunya cipta, rasa, karsa dan karya di dalam diri Penari Lengger. Selama prosesi diiringi dengan macapatan/kekidhungan yang maknanya berisi tentang keselamatan dan tolak bala.

Selama jamasan para Peserta mengenakan Pinjungan Jarik dengan sampur digunakan sebagai penutup bahu. Prosesi jamasan dilaksanakan pada pukul 14.00 hingga pukul 15.00 dan dilaksanakan oleh Mbah Ngadijo selaku Petugas Penjamas yang sebelumnya merupakan mantan Penari Lengger Pria.

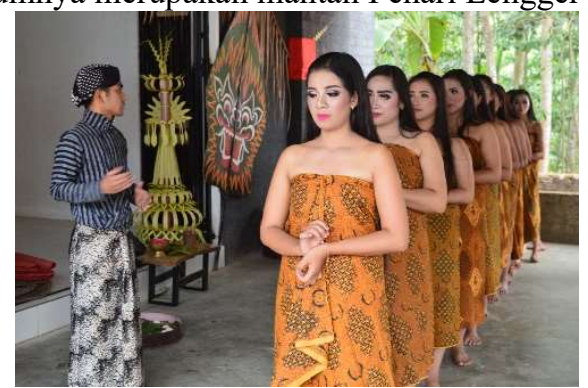

Gambar 2. Peserta bersiap mengikuti prosesi Jamasan

\section{Larung Sesajen}

Berikutnya setelah selesai melakukan jamasan, prosesi dilanjutkan dengan Larung Sesajen, yaitu melarung atau menghanyutkan 1 butir telur ayam kampung ke sungai. Hal ini mengandung nilai filosofis bahwa di dalam telur ada "wiji" atau bakal anak ayam yang akan tumbuh dan berkembang menjadi lebih bermanfaat. Demikian pula halnya dengan prosesi wisuda, merupakan langkah awal bagi Penari Lengger yang diharapkan akan terus berkembang dan membawa kemanfaatan bagi sesama (murakabi marang agung titah). Sesajen dilarung secara serentak dan masing-masing peserta memanjatkan doa dalam hati.

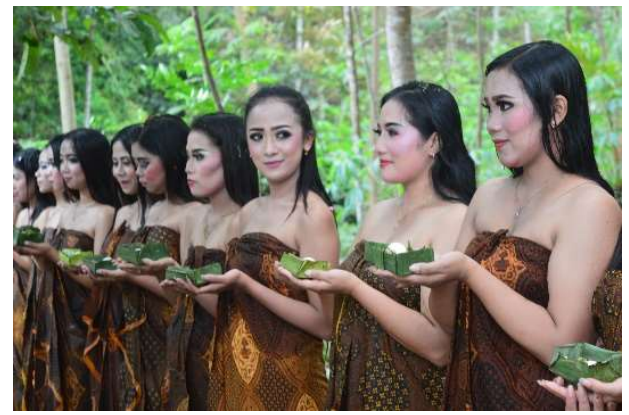

Gambar 3. Prosesi Larung Sesajen

Selama prosesi diiringi dengan macapatan atau kekhidungan yang maknanya berisi tentang 
keselamatan dan tolak bala. Prosesi ini dilaksanakan di Kali Wetan dan Peserta masih mengenakan pinjungan jarik dengan sampur digunakan sebagai penutup bahu.

\section{Prosesi Wisuda}

Setelah serangkaian ritual telah dilaksanakan, maka peserta siap diwisuda. Adapun urutannya, semua peserta naik ke panggung tempat wisuda, lalu duduk simpuh melingkar. Manggala Wisuda didampingi oleh 2 petugas, masing-masing membawa Kendi berisi tirta wening (air bening) dan bokor berisi air dan daun tawa. Satu persatu peserta meminum air kendi dan diperciki dengan daun tawa. Setelah semuanya selesai, Manggala Wisuda membacakan ikrar CATUR DHARMA LENGGER, diikuti para peserta.

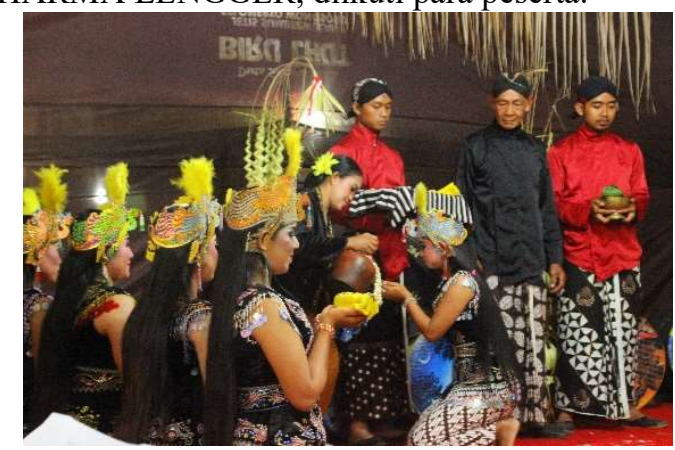

Gambar 4. Prosesi Wisuda

\section{Ikrar Catur Dharma Lengger}

Prosesi wisuda kemudian dilanjutkan dengan pengucapan ikrar Catur Dharma Lengger oleh para Peserta yaitu:

1. Manembah marang Sejatining Sesembahan, Gusti Ingkang Maha Agung nut kapitayanipun piyambak-piyambak. (Sembahlah Tuhan Yang Sejati Sesuai dengan Keyakinan Masing-Masing)

2. Setya tuhu dhateng Negara Kesatuan Republik Indonesia. (Bersumpah Setia kepada NKRI)

3. Tansah angudi luhuring Kabudayan Nasional, mliginipun Seni Lengger. (Selalu bangga dengan Budaya Nasional, terutama Seni Lengger)

4. Rumeksa lan ngugemi jejering Lengger ingkang utami. (Membangun dan Saling Menghargai Lengger yang Paling Utama)

\section{Penyematan Bros}

Selanjutnya prosesi pengukuhan peserta dengan penyematan bros Lengger oleh Manggala Wisuda. Bros Lengger tersebut harus dipakai saat pentas sebagai asesoris Penari Lengger. Dengan disematkannya bros Lengger tersebut, para Peserta sesuai dengan tahapan ritus wisuda telah resmi dikukuhkan menjadi Penari Lengger Wonosobo.

\section{Seblak Sampur}

Setelah proses penyematan bros Lengger, para Penari Lengger yang sudah diwisuda menuruni panggung tempat proses wisuda untuk menari Gambyong Lengger secara massal. Kemudian dilanjutkan dengan menari bersama dengan warga seDusun Giyanti.
Dengan dilaksanakannya tari Gambyong Lengger secara massal, prosesi Wisuda Lengger Giyanti pun berakhir. Hal ini pula menandakan bahwa peserta yang telah diwisuda telah siap baik secara lahir maupun batin untuk menyandang status sebagai Seorang Penari Lengger Giyanti.

\section{Pembahasan}

Pariwisata merupakan serangkaian proses, aktivitas dan hasil sebagai akibat dari terjadinya hubungan dan interaksi antara wisatawan, penyedia jasa pariwisata, stakeholder serta lingkungan yang terlibat dalam menarik dan menyediakan pelayanan kepada wisatawan (Goeldner \& Ritchie, 2009).

Salah satu segmen pariwisata yang tumbuh dengan cepat di dunia adalah festival dan event (Goeldner \& Ritchie, 2009). Kekuatan event sebagai katalisator untuk meningkatkan kunjungan wisatawan, meningkatkan lama tinggal dan pengeluaran wisatawan, membentuk citra destinasi pariwisata, serta menentukan posisi destinasi sehingga menjadikan destinasi pariwisata menjadi lebih kompetitif untuk target pasar, terletak pada kemampuannya dalam memenuhi tantangan imajinasi maupun harapan dari pengunjung atau penyelenggaranya, serta kemampuannya dalam menjelajahi alternatif kemungkinan dari ragam tradisi dan budaya yang potensial (Allen et al., 2002).

Menurut Allen (2002) gelaran yang merupakan ritus budaya atau perayaan tertentu yang diselenggarakan sebagai tanda peristiwa atau kejadian khusus, atau dibuat untuk mencapai tujuan sosial dan budaya tertentu, disebut sebagai spesial event. Merujuk pada definisi tersebut, gelaran Wisuda Lengger Giyanti dapat dikategorikan sebagai spesial event, karena tiga faktor, yaitu:

1. Wisuda Lengger Giyanti merupakan rangkaian dari prosesi Nyadran Tenongan yang berfungsi sebagai perwujudan rasa syukur warga Giyanti atas anugerah Tuhan Yang Maha Esa dan sebagai monumen budaya untuk mengingat terbentuknya Dusun Giyanti;

2. Wisuda Lengger Giyanti merupakan perwujudan kesadaran kolektif warga Giyanti untuk menumbuhkan kebanggaan lokal terhadap kesenian tradisional khas Wonosobo yang tumbuh dan berkembang di Dusun Giyanti;

3. Wisuda Lengger Giyanti menjadi aset budaya warga Giyanti untuk melestarikan kesenian tradisional Tari Lengger Wonosobo.

Peranan Wisuda Giyanti sebagai spesial event di Kabupaten Wonosobo, menurut Goeldner dan Ritchie (2009), antara lain:

1. Merayakan keunikan lokal masyarakat Dusun Giyanti;

2. Mempromosikan Lengger Giyanti sebagai kearifan lokal Dusun Giyanti sekaligus mencitrakan Dusun Giyanti sebagai dusun yang menghasilkan Penari Lengger;

3. Mengembangkan kebanggaan masyarakat Giyanti terhadap kesenian Lengger; dan 
4. Meningkatkan kesejahteraan ekonomi masyarakat di Dusun Giyanti.

Menurut penelitian (Kelly \& Fairley, 2018) event dengan skala kecil seperti Wisuda Lengger Giyanti dapat dimanfaatkan untuk kepentingan pariwisata (meningkatkan jumlah kunjungan wisatawan, meningkatkan lama tinggal dan jumlah pengeluaran wisatawan) hanya dapat terwujud apabila terjadi kolaborasi antara penyelenggara event, mitra pendanaan (sponsorship baik dari pemerintah maupun swasta), dan operator pariwisata (biro perjalanan wisata).

\section{SIMPULAN}

Dari hasil analisis terhadap event budaya Wisuda Lengger Giyanti dapat diidentifikasi aspek-aspek budaya yang terkandung dalam gelaran ini sebagai daya tarik wisata di Wonosobo antara lain: aspek sejarah berdirinya Dusun Giyanti yang memiliki hubungan dengan sejarah Perjanjian Giyanti, upacara tradisi Nyadran Tenongan, dan kesenian tradisional khas Wonosobo berupa Tari Lengger. Karena fokus penelitian ini hanya kepada aspek-aspek kebudayaan dalam Wisuda Lengger Giyanti, penelitian selanjutnya dapat mempertimbangkan untuk meneliti peran Event Budaya Lengger Giyanti dalam meningkatkan kesejahteraan ekonomi masyarakat di Dusun Giyanti.

\section{UCAPAN TERIMA KASIH}

Ucapan terima kasih kepada Bapak Tatag Taufani selaku Narasumber Penyelenggara Event Wisuda Lengger Giyanti. Juga kepada Bapak Dedek Diansyah, Staf Dinas Kebudayaan dan Pariwisata Kabupaten Wonosobo, yang telah membantu melengkapi data-data dan informasi tentang penyelenggaraan Event Wisuda Lengger Giyanti.

\section{DAFTAR PUSTAKA}

Pustaka yang berupa majalah/jurnal ilmiah:

Aristrawati, N. L. P. (2018). Evaluasi Parade OgohOgoh Sebagai Pendukung Pengembangan Pariwisata Budaya Di Kota Denpasar. Jurnal Master Pariwisata (JUMPA), 2, 147. https://doi.org/10.24843/jumpa.2018.v05.i01.p0 8

Chhabra, D. (2019). Authenticity And The Authentication Of Heritage : dialogical Perceptiveness. Journal of Heritage Tourism, $0(0), 1-7$. https://doi.org/10.1080/1743873X.2019.164434 0

Dai, T., Hein, C., \& Zhang, T. (2019). Understanding How Amsterdam City Tourism Marketing Addresses Cruise Tourists' motivations Regarding Culture. Tourism Management Perspectives, 29(December 2018), 157-165. https://doi.org/10.1016/j.tmp.2018.12.001
Kelly, D. M., \& Fairley, S. (2018). What About The Event? How do Tourism Leveraging Strategies Affect Small-Scale Events? Tourism Management, 64, 335-345. https://doi.org/10.1016/j.tourman.2017.09.009

Laing, J. (2018). Festival And Event Tourism Research : Current And Future Perspectives. Tourism Management Perspectives, 25(September 2017), 165-168. https://doi.org/10.1016/j.tmp.2017.11.024

Lee, K. Y., \& Lee, H. (2019). Traditional Costume Experience At A Cultural Heritage Festival. Tourism Management Perspectives, 32(July), 100555. https://doi.org/10.1016/j.tmp.2019.100555

Liu, Y. De. (2014). Cultural Events and Cultural Tourism Development: Lessons from the European Capitals of Culture. European Planning Studies, 22(3), 498-514. https://doi.org/10.1080/09654313.2012.752442

Macleod, D. (2006). Cultural commodification And Tourism: A Very Special Relationship. Tourism, Culture and Communication, 6(2), 71-84. https://doi.org/10.3727/109830406777410580

Puspita, D., \& Sulandari, S. (2016). Strategi Pengelolaan Desa Wisata Giyanti, Kabupaten Wonosobo. Journal Of Public Policy And Management Review, 5(Nomor 2). https://doi.org/DOI: 10.14710/jppmr.v5i2.10697

Rahayu, I. (2018). Dampak Penyelenggaraan Event Pariwisata Dragon Boat Race Di Kota Tanjungpinang. Jurnal Master Pariwisata (JUMPA), 05, 211. https://doi.org/10.24843/jumpa.2018.v05.i01.p1 1

Richards, G., \& Wilson, J. (2004). The impact Of Cultural Events On City Image: Rotterdam, Cultural Capital Of Europe 2001. Urban Studies, 41(10), 1931-1951. https://doi.org/10.1080/0042098042000256323

Risteski, M., \& Risteski, N. (2015). Determining Quality Of Tourism Events. Hotel Link.

Ristiawan, R. R. (2018). Culture as Tourism Attraction: Commodification and Politicization of Culture in Kembangarum Tourism Village, Yogyakarta Special Region, Indonesia. GADJAH MADA JOURNAL OF TOURISM STUDIES, 1(1), 12-22.

Santa, E. Dela, \& Tiatco, S. A. (2019). Tourism, Heritage And Cultural Performance : Developing A Modality Of Heritage Tourism. Tourism Management Perspectives, 31(June), 301-309.

https://doi.org/10.1016/j.tmp.2019.06.001

Szmigin, I., Bengry-howell, A., Morey, Y., Griffin, C., \& Riley, S. (2017). Socio-Spatial Authenticity At Co-Created Music Festivals. Annals of Tourism Research, 63, 1-11. https://doi.org/10.1016/j.annals.2016.12.007 
Zhou, Q. (Bill), Zhang, J., Zhang, H., \& Li, X. (Robert). (2018). Is All Authenticity Accepted By Tourists And Residents? The concept, Dimensions And Formation Mechanism Of Negative Authenticity. Tourism Management, $67,59-70$.

https://doi.org/10.1016/j.tourman.2017.12.024

Pustaka yang berupa judul buku:

Allen, J., O'Toole, W., McDonnel, I., \& Harris, R. (2002). Festival and Special Event Management (Second Edi). John Wiley \& Sons Australia, Ltd.
Goeldner, C. R., \& Ritchie, J. R. B. (2009). Tourism: Principles, Practices, Philosophies (11th ed.). John Wiley \& Sons, Inc., Hoboken, New Jersey.

\section{Pustaka yang berupa hasil wawancara:}

Taufani, T. (2019). Laporan Wawancara Mendalam Dengan Penyelenggara Event Wisuda Lengger Giyanti. 